\title{
Desenvolvimento local e apropriação dos processos econômicos ${ }^{1}$
}

\author{
Ladislau Dowbor ${ }^{2}$
}

\section{Resumo}

A partir de conceitos de Milton Santos e outros teóricos, o presente artigo mostra o imenso potencial do "circuito inferior" da economia, em termos produtivos e de redução das desigualdades herdadas, por meio da inclusão socioprodutiva com sustentabilidade e o estímulo ao desenvolvimento local. Destacamos essa contribuição para repensarmos a dimensão territorial - gestão local, de regiões e de microrregiões - do desenvolvimento e sua importância na construção de novas dinâmicas produtivas, na busca de um outro mundo e outra ciência econômica, incluindo a importância da gestão racional do município, da participação comunitária e das novas formas de comunicação.

\section{Palavras-chave}

Desenvolvimento local, territorialidade, gestão local, circuito inferior da economia.

1 Neste artigo, foram aproveitados apontamentos utilizados em diversos trabalhos. Para textos completos, ver o nosso $O$ que é poder local?, editado pela Brasiliense em 2008; Democracia econômica, pela editora Vozes em 2008, e o relatório de pesquisa Política Nacional de Apoio ao Desenvolvimento Local - todos disponíveis em http://dowbor.org

2 Doutor em Ciências Econômicas pela Escola Central de Planejamento e Estatística de Varsóvia, professor titular da Pontifícia Universidade Católica de São Paulo (PUC-SP) e consultor de diversas agências das Nações Unidas. E-mail: ladislau@dowbor.org 


\title{
Local Development and economic empowerment
}

\section{Ladislau Dowbor}

\begin{abstract}
Milton Santos is the author of key contributions to the spatial dimension of development. He was also deeply concerned with the social dimension of the economy, and his notion of the "lower circuit" has been instrumental in stimulating analysis on survival strategies at the bottom of the pyramid. Unlike the big corporations and their global logic of accumulation, the lower circuit is basically local and close to community. This view is essential for the organization of a system of support for local development through the productive inclusion and the notion of "decent" employment. The paper relies heavily on a research on productive inclusion in Brazil, using Milton Santos' categories.
\end{abstract}

Keywords

Local development, empowerment, lower economic circuit. 


$$
0
$$


to de projetos voltados para o crescimento econômico. É uma dinâmica cultural e política que transforma a vida social.

Inúmeros municípios, regiões, comunidades, cidades - as diferentes subdivisões que compõem os territórios locais - se deram conta desta dimensão do desenvolvimento. Construíram espaços de mobilização democrática e produtiva, onde os atores sociais - administrações públicas, empresas, sindicatos, organizações da sociedade civil - se organizam para mobilizar o potencial local. Deixaram de esperar, arregaçaram as mangas e já dinamizam um conjunto de atividades, partindo de novos pactos e arranjos sociais e da mobilização dos recursos disponíveis. Os aportes externos são importantes, mas devem existir como complementos a uma dinâmica que pertence à própria sociedade local.

Durante a gestão do Presidente Lula, foram desenvolvidos esforços importantes de inclusão e mobilização na base da sociedade. O programa Bolsa Família atinge mais de 48 milhões de cidadãos, um quarto da população do país. A capacidade de compra do salário mínimo aumentou de forma significativa durante o período, melhorando a situação de grande massa de assalariados e de aposentados. Foram gerados aproximadamente 13 milhões de empregos. O programa Territórios da Cidadania está investindo 20 bilhões de reais em 120 regiões do país. O saneamento básico teve seus recursos triplicados, atingindo diretamente a população de mais baixa renda. A abertura de espaço nas universidades para jovens de poucos recursos criou novo alento para indivíduos da comunidade mais pobre. $\mathrm{O}$ Brasil começa a colher bons resultados no combate à pobreza e à desigualdade na distribuição de renda.

Todavia, para que esse avanço seja sustentável, é imprescindível articular e generalizar novos passos de inclusão produtiva. No momento em que o poder público decide, finalmente, implementar políticas abrangentes de incorporação da grande massa de excluídos do desenvolvimento nacional, é importante olhar para o conjunto de ações que brotam da própria iniciativa local, definindo mecanismos para estimulá-lo, ou ainda para reduzir os entraves que podem vir a bloqueá-lo.

Não se trata de uma alternativa entre dar o peixe ou ensinar a pescar. Ninguém consegue pescar passando fome. Mas trata-se de municiar as comunidades para que possam participar de forma ativa do crescimento nacional, mediante iniciativas autônomas de desenvolvimento local, capazes de gerar, relativamente aos programas de redistribuição, o complemento estrutural de inserção econômica e social.

Apresentaremos, como ilustração, alguns exemplos concretos de distorções e entraves que tolhem, na atualidade, o avanço das iniciativas locais de desenvolvimento. O município de São Luis, no Maranhão, para 
renovar equipamentos escolares, teve de fazer, nos termos da lei, uma licitação nacional que foi vencida por empresa de Santa Catarina. Portanto, as carteiras escolares viajaram 3 mil quilômetros, quando não faltam pequenas empresas moveleiras locais.

O Grupo de Trabalho Amazônico - GTA, importante articulação que compreende cerca de 530 organizações promotoras de desenvolvimento local de regiões isoladas, não pode utilizar rádios comunitárias para se comunicar e mobilizar a população, pois esse tipo de emissora, por lei, só pode funcionar no raio de mil metros, distância que é inexpressiva na vastidão da Amazônia.

Promove-se a criação de cooperativas de crédito para escapar aos juros da intermediação privada, mas o Banco Central ainda leva, em média, nove meses para aprovar uma cooperativa, tornando o processo moroso e difícil. Além desses casos, quem já tentou abrir ou fechar uma pequena empresa conhece os entraves burocráticos a serem enfrentados.

Do ponto de vista da comunidade local, o que se propõe é uma profunda mudança de enfoque. Trata-se de trocar a pergunta "o que o governo pode fazer por nós?", por "como o governo pode apoiar o que estamos empreendendo?”. Do ponto de vista das diversas instâncias de governo, das instituições públicas ou privadas de apoio, e da própria academia, trata-se de entender que, somando-se às iniciativas que a comunidade assimila como suas, a produtividade dos esforços aumenta, maximizando resultados.

É corrente a convicção, em setores das elites brasileiras, de que as pessoas na base da sociedade representam um ônus. Na realidade, é preciso reconhecer que essas pessoas foram privadas das oportunidades a que têm direito e que oportunidades se organizam e se multiplicam. Apostar na capacidade produtiva da base social do país é essencial no atual processo histórico de construção nacional, assim como é primordial eliminar os entraves que impedem esse potencial de se materializar. Os pobres não vivem em situação precária por falta de criatividade ou vontade, mas por insuficiência e pouca articulação dos sistemas de apoio.

Existe no país um sólido sistema de fomento à grande empresa. Os grandes produtores rurais contam com mecanismos amplos de apoio, tanto financeiro, como de abertura de mercados no exterior. Pela própria escala de produção, os grandes grupos industriais têm como contratar consultorias especializadas para a renovação tecnológica, ou planejar campanhas publicitárias para divulgar seus produtos. Para os pequenos empresários e produtores, existem iniciativas pontuais, mas nada que possa se comparar, nada que possa ser qualificado, efetivamente, como uma verdadeira política nacional de apoio ao desenvolvimento local. 
Não se propõe aqui substituir as iniciativas locais autônomas por algum tipo de burocracia federal. Pelo contrário, trata-se de liberar os potenciais que existem, retirando entraves. Há centenas ou milhares de iniciativas em curso, que demonstram bem a necessidade dessa nova política nacional. A Lei Geral da Micro e Pequena Empresa deve constituir uma ajuda significativa, inclusive porque permite ampliar o uso de recursos públicos para compras locais. Os Arranjos Produtivos Locais (APLs), organizados pelo Sebrae, e que envolvem o Ministério da Integração Nacional e governos estaduais, constituem importante esforço de articulação entre iniciativas de um mesmo território, para torná-las mais sinérgicas. A expansão de experiências inovadoras, como o orçamento participativo, tende a racionalizar o uso dos recursos públicos. A universalização do microcrédito, em particular no quadro do Banco do Nordeste Brasileiro, busca democratizar o financiamento. Redes como a Pastoral da Criança mostram como se pode alcançar resultados impressionantes mobilizando a capacidade local para enfrentar os problemas.

Tais iniciativas envolvem administrações públicas de diversos escalões, o sistema "S" nos seus diversos componentes, empresas, organizações da sociedade civil, academia, redes de pesquisa como Empresa Brasileira de Pesquisa Agropecuária (Embrapa) e outros. O volume de iniciativas locais tem aumentado fortemente, alimentado agora pelo maior fluxo de recursos circulando na base mais pobre da população.

Já apóiam e orientam esse tipo de trabalho instituições de pesquisa e de assessoria técnica, como a Fundação Getúlio Vargas, de São Paulo, por meio do seu programa Gestão Pública e Cidadania; o Instituto Brasileiro de Administração Municipal (Ibam), do Rio de Janeiro; o Centro de Estudos e Pesquisas de Administração Municipal (Cepam) e o Instituto Pólis, em São Paulo; a Fundação João Pinheiro, de Minas Gerais, e dezenas de outras. Só a FGV-SP possui um cadastro com 7.500 experiências inovadoras desse tipo. $\mathrm{O}$ Pólis trabalha com mais de mil inovações, publicadas no Dicas Municipais, a Fundação Banco do Brasil acompanha cerca de 230 experiências por intermédio da Rede de Tecnologias Socais.

Cabe ressaltar que experiências de desenvolvimento local bem estruturadas têm como característica central o fato de se apoiarem quase sempre em parcerias. Portanto, não se trata apenas de iniciativas pontuais, mas de organizações plurais que se articulam para dinamizar uma região, envolvendo diversos atores. As parcerias permitem que modalidades distintas de iniciativas isoladas tornem-se coerentes e complementares, em vez de fragmentadas e dispersas.

Quando se pensa numa empresa, se pensa numa unidade de grande densidade organizacional. Não se pode imaginar uma economia que 
seja produtiva sem que as suas empresas o sejam. Da mesma forma que a economia se apóia num conjunto de empresas, o desenvolvimento do país precisa se apoiar em unidades territoriais básicas, que têm de ser administradas de forma racional e produtiva. Na realidade, os municípios constituem os blocos com os quais se constrói o país. Ainda que as instâncias superiores de gestão sejam importantes, criando grandes infraestruturas, assegurando equilíbrio macroeconômico e desenvolvendo políticas tecnológicas, todo esse empenho deve se materializar em territórios bem geridos, sendo apropriado de forma inteligente, democrática e participativa pelos atores locais.

Por mais esforços que se façam no plano federal ou estadual, quem tem de pôr ordem na própria casa, em última instância, é o município. Pois é nesse espaço onde os atores sociais conhecem os seus problemas e podem se articular de forma criativa, organizando os seus sistemas de informação e os monitorando. Portanto, a questão chave que se coloca é a seguinte: como ajudar os 5.564 municípios que estão na base do país a serem administrados de forma competente? Isto porque, melhorando a capacidade de gestão na base do país, há um avanço não apenas da produtividade local, mas também da produtividade sistêmica do conjunto de agentes econômicos e sociais. Ao assegurar o apoio descentralizado ao pequeno produtor e aos processos participativos de gestão local, contribui-se para a própria democratização dos processos locais de decisão.

No conjunto, é necessário que chegue mais apoio. É necessário também que o apoio seja menos fragmentado e mais integrado no nível local. É preciso assegurar, no entanto, que esse apoio não substitua, mas fomente a apropriação local do processo de desenvolvimento. É preciso também formar pessoas para que os recursos sejam mais bem aproveitados. Trata-se de gerar soluções institucionais menos rígidas, facilitando a estruturação de consórcios intermunicipais, de parcerias entre os diversos setores, de conselhos, foros e agências de desenvolvimento. A Prefeitura e a Câmara de Vereadores formam apenas parte desse universo. Portanto, é necessário que haja menos burocracia, mais instrumentos e meios, mais flexibilidade na gestão, mais participação organizada dos atores locais, mais formação e informação, soluções que apontem para o pleno emprego e para a sustentabilidade do processo.

Por que insistir na dimensão territorial - gestão local, de regiões e de microrregiões - do desenvolvimento, quando já existem sistemas setoriais de apoio como o Senac para o comércio, a Embrapa para a pesquisa agrícola, escolas técnicas para a formação profissional e numerosas outras unidades de apoio? Porque a produtividade sistêmica exige integração e coerência no conjunto do processo. Por isso, não adianta assegurar formação profissional 
se não houver recursos para investimentos que gerem empregos, assim como não será suficiente o investimento se não houver apoio tecnológico.

Toda empresa busca alocar racionalmente os fatores de produção. Para aprender a fazê-lo, existem os cursos de administração de empresas, que ensinam como gerir de maneira integrada e eficiente o conjunto dos recursos disponíveis. De forma semelhante, a unidade territorial deve aprender a otimizar o uso de seus recursos naturais, humanos, sociais, culturais e econômicos. E sempre de forma democrática, pois os membros da comunidade, neste caso, são os donos do empreendimento.

É viável se pensar a cidade como espaço de acumulação? Podemos sem dúvida pensar uma empresa como unidade de acumulação, e os gestores de uma empresa têm à sua disposição um conjunto de técnicas para assegurar que os recursos disponíveis sejam plenamente utilizados, que as diversas atividades empresariais formem um conjunto coerente, que os processos e ritmos dos diversos departamentos sejam compatíveis. Ou seja, a empresa proclama a mão invisível, mas apenas lá fora. Dentro da empresa, impera a racionalidade, por vezes opressiva, por vezes hipócrita, por vezes corrupta, e, muitas vezes, simplesmente eficiente, mas no conjunto ninguém nega a necessidade de uma gestão racional.

O município pode ser gerido racionalmente? A própria prefeitura é uma unidade gestora, e presta contas. Mas uma cidade, com o seu contorno rural, pode ser vista como espaço de processos coerentemente articulados e integrados, visando uma produtividade sistêmica elevada? Até recentemente, o problema não aparecia como relevante, pois havia população urbana apenas em algumas capitais, e o grosso da população constituía uma população rural dispersa. O resultado disso era que governo era coisa da capital, onde famílias ricas acumulavam a direção empresarial e a direção política. Atualmente, o Brasil tem 82\% de população urbana, distribuída por cerca de 5.600 municípios, que constituem a unidade básica de organização política, econômica, social e cultural. E a Constituição de 1988 concedeu autonomia a esses municípios. É, portanto, possível se pensar a racionalidade do conjunto - o país - sem resgatar a coerência interna das unidades básicas, os municípios?

Essa visão constitui um deslocamento de perspectiva. De certa maneira, deixamos de olhar o município como o lugar distante, onde os projetos do governo central ou as iniciativas da grande empresa devem chegar, para considerar o município como bloco básico de construção do conjunto. Uma economia poderia funcionar bem se as suas empresas fossem geridas de forma caótica? Adotando o mesmo raciocínio para a nação, podemos nos perguntar se é viável uma racionalidade nacional sem se promover a racionalidade do conjunto das unidades que a compõem. 
Em particular, ao se deslocar boa parte das iniciativas do desenvolvimento para o nível local, aproxima-se a decisão do espaço onde está o cidadão que pode efetivamente participar, enfrentando em particular a questão das periferias urbanas, que se tornaram a forma dominante de manifestação da nossa tragédia social.

John Friedmann coloca com clareza a mudança de foco em termos tanto de objetivos como do mecanismo correspondente de regulação que a territorialização exige:

O modelo mainstream de crescimento econômico expressa o anseio do capital global por uma economia "sem fronteiras" na qual não haja nem interesses organizados nem poderes intermediando os centros de decisão corporativa por um lado, e trabalhadores e consumidores individuais por outro. Na ideologia do capital, este tipo de economia se chama "livre". Reduz os interesses territoriais a um mínimo de "lei e ordem", como assegurar o respeito aos contratos e a manutenção da ordem nas ruas. Esta visão traz também a expectativa que os Estados territoriais lidarão da melhor forma que puderem com as consequências sociais do investimento privado e das decisões produtivas, tais como o esgotamento de recursos, desemprego, pauperização, poluição, desflorestamento e outros problemas das "áreas comuns". A territorialidade chama a nossa atenção para o ambiente físico: a base de recursos da economia, o valor estético de paisagens tradicionais, e a qualidade de vida no ambiente construído onde têm lugar todas as nossas ações e que afetam a nossa vida, direta e indiretamente. ${ }^{3}$

Friedmann coloca com força a compreensão de que além da regulação empresarial e da regulação governamental, existe um processo de regulação crescente na base da sociedade, a partir do local onde as pessoas vivem, na linha do que chamou de "participatory governance".

Um desenvolvimento alternativo é centrado nas pessoas e no seu ambiente, mais do que na produção e nos lucros. Da mesma forma que o paradigma dominante aborda a questão do crescimento econômico na perspectiva da empresa, que é o fundamento da economia neoclássica, um desenvolvimento alternativo, baseado, como deve ser, no espaço de vida da sociedade civil, aborda a questão da melhoria das condições de vida e das vivências na perspectiva do domicílio. ${ }^{4}$

3 FRIEDMANN, John. Empowerment: the politics of alternative development. Blackwell: Cambridge, 1992. p. 31 e 35 .

4. Idem, ibidem, p. 35 . 
Esses objetivos nos levam ao conceito de articulação da regulação local com o poder do Estado.

Apesar de apontar para uma política localmente enraizada, um desenvolvimento alternativo requer um Estado forte para implementar as suas políticas. Um Estado forte, no entanto, não precisa ser pesado no topo, com uma burocracia arrogante e enrijecedora. Será mais bem um Estado ágil e que responde e presta conta aos seus cidadãos. É um Estado que se apóia amplamente numa democracia inclusiva na qual os poderes para administrar os problemas serão idealmente manejados localmente, restituídos às unidades locais de governança e ao próprio povo, organizado nas suas comunidades. ${ }^{5}$

Com isso, a participação comunitária, por meio do seu envolvimento direto nos assuntos da gestão racional dos recursos localmente disponíveis, aparece como um mecanismo regulador complementar, acrescentando-se ao mercado que constitui o mecanismo regulador dominante do setor empresarial, e ao direito público administrativo que rege a ação dos órgãos do Estado. Como a qualidade de vida da comunidade representa em última instância o resultado que se quer do desenvolvimento, a demanda organizada da comunidade passa a constituir o "norte" orientador, para a produtividade sistêmica, da mesma forma como a demanda do consumidor individual o era para os processos produtivos tradicionais.

Os trabalhos de Robert Putnam trouxeram fortes avanços neste plano, pois mostram a que ponto os mecanismos participativos não só complementam a regulação do Estado e do mercado, mas constituem uma condição importante da eficiência destes mecanismos. O capital social aparece como fator importante da qualidade da governança de determinado território. O estudo sobre a Itália já tornou-se um clássico, mas é sobretudo na análise dos Estados Unidos que Putnam mostra a importância da capacidade de organização da sociedade em torno dos seus interesses

5 Idem, ibidem, p. 35 e 36 . O conceito de "empowerment" tem sido traduzido de forma óbvia por empoderamento, e já foi apropriado na nossa literatura, tal como empoderamiento na literatura hispânica. Note-se que Friedmann trabalha com o conceito de desenvolvimento local, mas na perspectiva de territorialidades (no plural) articuladas. (Para ampliar a questão ver FRIEDMANN, John. op. cit., p. 133, em que trata das definições correspondentes). Estamos além de um "O negócio é ser pequeno". 
- a dimensão participativa da regulação econômica e política - como um elemento chave da racionalidade do desenvolvimento em geral $^{6}$.

Do ponto de vista da teoria econômica, o processo em si é interessante, pois fomos gradualmente passando da visão do capital físico acumulado -, que ainda ocupa o papel central em O capital, de Marx -, para a compreensão do papel maior do capital financeiro, evoluindo para a recente tomada de consciência da importância do capital natural, que estamos esgotando no planeta, até chegarmos à compreensão mais ampla de capital humano, que se tornou crucial com os avanços tecnológicos, e do capital social, que representa, de maneira mais ampla, a maturidade e coesão do tecido social que sustenta o conjunto. A progressão ao mesmo tempo reflete a ampliação do conceito de economia, e a articulação da ciência econômica com as outras ciências sociais. O conceito de capital social está sem dúvida na moda neste momento, mas na realidade o importante é compreender a necessidade de se organizar a alocação racional de capital no sentido mais complexo ${ }^{7}$.

A visão tradicional seria a de que os municípios constituem a base de uma pirâmide, e esta "verticalidade" teórica está profundamente ancorada nas nossas convicções. Na realidade, as novas orientações apontam para a articulação horizontal dos atores sociais dentro do município, e para as formas intermunicipais de gestão (por exemplo, consórcios intermunicipais de saúde, comitês de bacias hidrográficas, conselhos regionais de desenvolvimento, redes de cidades-irmãs), permitindo articulações regionais complexas. O resultado disso, é que as próprias comunidades deixam ser "pequenas demais" para serem viáveis, pois podem se articular de maneira criativa e diferenciada nas diversas territorialidades. $\mathrm{O}$ ponto chave aqui é a iniciativa, no sentimento de apropriação das políticas, que é devolvida no espaço local, onde as pessoas podem participar diretamente, pois conhecem a realidade e a escala de decisão coincide com o seu horizonte de conhecimento.

Isto muda profundamente o que poderíamos chamar de cultura do desenvolvimento. Uma comunidade deixa de ser um receptor passivo de decisões longínquas, seja do Estado que vai "doar" um centro de saúde, ou de uma empresa que chegará e poderá “dar” empregos. O

6 PUTNAM, Robert. Bowling alone: the collapse and revival of American community. New York: Simon \& Schuster, 2ooo; o seu estudo sobre a Itália, Making Democracy Work, foi traduzido no Brasil como Comunidade e democracia.

7 É a visão que desenvolvemos no nosso A reprodução social, partindo da compreensão de que a reprodução do capital constitui apenas um segmento - ainda que central - do processo de desenvolvimento. Passamos assim a ver o desenvolvimento como articulação das diversas formas de capital em territórios diferenciados e complementares. 
desenvolvimento deixa de ser uma coisa que se espera pacientemente, torna-se algo que se faz, inclusive no aspecto da organização dos aportes externos. A cidadania política é complementada pela cidadania econômica, e gera-se o sentimento de apropriação e domínio da sua própria realidade ${ }^{8}$.

Uma dimensão importante desse processo é a mudança do paradigma da comunicação. "O espaço está morto” comenta um articulista americano, ao ver a conectividade planetária instantânea dos que trabalham com aplicações financeiras. É um exagero evidente, as pessoas ainda moram numa cidade concreta, olham o pôr do sol na beira de um rio concreto. Mas o fato de a informação estar instantaneamente disponível em qualquer parte do planeta muda drasticamente o nosso universo de reflexão.

No município de Piraí, no interior do Estado do Rio, criou-se um sistema público de acesso banda larga na Internet para todos. Foi um pequeno investimento público, mas representou um grande fator de produtividade para as empresas e os comércios locais, que passaram a se relacionar com fornecedores e consumidores em escala muito mais ampla. A taxa um pouco mais elevada, paga pelos empresários, permitiu generalizar o acesso banda larga até nos bairros mais pobres, por 35 reais por mês. O impacto de inclusão digital foi profundo, mas o interessante é que a generalização da conectividade permitiu melhorar a produtividade de todos os atores sociais do município, das escolas, do sistema de saúde e assim por diante. Essa experiência constitui uma forte ilustração de como podem ser articulados os espaços global, regional e local, por meio das formas modernas de conectividade, num processo em que a comunidade é dona do seu próprio processo de desenvolvimento, em vez de aguardar que uma multinacional abra um resort e fantasie a população local com trajes típicos ${ }^{9}$.

8 Um aporte interessante neste plano é o de Bruno Frey e Alois Stutzer que, no seu estudo sobre felicidade e economia, insistem na importância relativa do processo pelo qual chegamos a resultados econômicos. O sentimento de apropriação, de ser sujeito criativo de um processo, constitui frequentemente uma motivação mais importante do que apenas o resultado (output) sob forma de vantagens econômicas. FREY, Bruno S. and STUTZER, Alois. Happiness and economics. Princeton: Princeton University Press, 2002.

9 O projeto Piraí Digital resultou de uma parceria entre o município e a Universidade Federal Fluminense, sob orientação do Prof. Franklin Coelho. Atualmente, vários municípios da região estão seguindo o exemplo e criando um eixo digital integrado regional. Este enfoque, de se gerar com serviços públicos iniciativas que tornam todos os atores sociais mais produtivos, generalizando economias externas, é estudado de maneira sistemática por Carlos Trigiglia, no livro Sviluppo locale. Roma: Laterza, 2005 . 
O wi-fi é a tecnologia que permite, havendo um ponto emissor, que se possa acessar a internet sem fio em todo o ambiente da casa, ou do escritório. Na atualidade, essa tecnologia está sendo usada em espaços urbanos, permitindo que as pessoas trabalhem ou estudem em qualquer lugar. É a versão computador do telefone celular, cobrindo todo um espaço urbano. Gerou-se, portanto, uma corrida nas cidades para que se instalem retransmissores de forma que todo o espaço urbano esteja coberto pelo sinal. Chamam isso de "municipal mesh wi-fi networking". Segundo artigo publicado pelo New Scientist, "as redes públicas wi-fi terão também impacto nos $w i$ - $f$ instalados em residências, escolas, livrarias e cafés. Sistemas que abrangem toda uma cidade e ligam um conjunto de pontos wi-fi para formar uma teia ('mesh'), onde os sinais de rádio recebidos num ponto saltam de antena para antena até encontrarem alguém que está conectado na $n e t^{\text {’10 }}$.

Essa tecnologia que permite conectividade de todo o espaço urbano já é barata. Por exemplo, na cidade de Philadelphia, nos EUA, "cerca de 4 mil postes nos 320 quilômetros quadrados da cidade terão antenas $w i-f$, que cobrirão a cidade com sinal e banda larga sem fio. A promessa é de um acesso pela internet de 1-megabit/segundo por menos de 10 dólares por mês, comparado com 45 dólares para a conexão cabo hoje"11. A cidade de Taipei, em Taiwan, na China, está generalizando o sistema com uma taxa geral de 12 dólares ao mês.

A convergência teórica mencionada aponta, assim, para um conjunto de estudos centrados nos diversos vetores que constroem a modernidade. Os trabalhos de Manuel Castells sobre a sociedade em rede apontam para a facilidade maior desta regulação local, aproveitando a conectividade horizontal do conjunto de atores sociais que participam do processo de desenvolvimento.

Já os estudos de Pierre Lévy sobre a inteligência coletiva permitem vislumbrar uma sinergia de esforços sociais por meio da convergência das informações e dos conhecimentos de uma comunidade territorial articulada com comunidades virtuais. Os trabalhos de Ignacy Sachs, partindo da preocupação da sustentabilidade dos processos de desenvolvimento, evidencia a importância dos recursos subutilizados - herança das discussões sobre planejamento econômico na Polônia socialista, tempos de Lange e Kalecki - que existem em cada localidade ${ }^{12}$.

10 MARKS, Paul. Cities race to reap the rewards of wireless net for all. New Scientist, 25 mar. 20o6. Disponível em: http://www.newscientist.com/ Acesso em: jul. 2010.

11 Idem, ibidem.

12 CASTELLS, Manuel. The rise of the network society. Blackwell: Oxford, 1996; LÉVY, Pierre Lévy. L'intelligence collective. Paris: La Découverte, 1994; SACHS, Ignacy. Inclusão social pelo trabalho. Rio de Janeiro: Garamond/Sebrae, 2003. 
Voltamos aqui, de certa maneira, ao nosso ponto de partida, para a visão que Milton Santos nos trouxe sobre o território e a sua importância na construção de novas dinâmicas produtivas.

Outro nordestino, Celso Furtado, nos mostrou a visão de uma ciência econômica propositiva, que aponta para o caminho de construção dos resultados que queremos, em vez de nos perdermos em prognósticos sobre a nervosidade do mercado financeiro. Outro ainda, Paulo Freire, nos apresentou a visão da imensa importância da cultura nos processos de mudança. Todos trabalharam com os desafios apontados por Josué de Castro. Da terra "pobre" nasceram as mais ricas visões.

O resultado, evidentemente, deve ser a nossa prosaica qualidade de vida, numa visão sustentável. Paulo Freire dizia simplesmente que queria “uma sociedade menos malvada". A imagem da qualidade de vida nos remete a um bairro agradável, com razoável prosperidade, saúde, riqueza cultural, equidade e segurança: grande parte destas coisas se organizam localmente, e ter uma economia gerida por resultados implica que estes resultados sejam, em grande parte, determinados pelas comunidades criativas e diferenciadas que temos, e não necessariamente reproduzindo um modelo padrão decidido em cima. Assim, ao associarmos desenvolvimento local com o conceito de cultura do desenvolvimento estamos apontando para uma reconciliação entre a democracia política e a democracia econômica. Todavia, esse possível outro mundo vai exigir também uma outra ciência econômica, que incorpore essas dimensões ${ }^{13}$.

13 Um dossiê extremamente rico sobre as dimensões econômicas, políticas e culturais da construção de alternativas pode ser encontrado em Pour changer le monde, n. 83, oct./nov., 2005 de Manière de voir. Uma publicação do Le Monde Diplomatique, que reúne artigos essenciais sobre um tema escolhido, a cada dois meses. Dois artigos em particular, de Claude Julien e de José Saramago, focam as relações entre a economia e a política, e mostram a que ponto a nossa correria para fazer funcionar a política por meio de mexidas na legislação eleitoral, sem enfrentar o grande poder econômico, que tudo compra e absorve, simplesmente não resolve. Na nossa visão, resgatar o potencial econômico da gestão local não envolve apenas eficiência de gestão, mas também concentrar uma parte maior da economia na escala onde as pessoas têm sobre ela um controle maior, resgatando, assim, o controle sobre as suas próprias vidas. Uma economia que passa a pertencer ao cidadão abre mais espaço para uma cidadania política real. 